\title{
Retrospective from the Literature on the Clinical Implications of the Application of Physiognomic Fillings
}

ISSN: 2637-7764

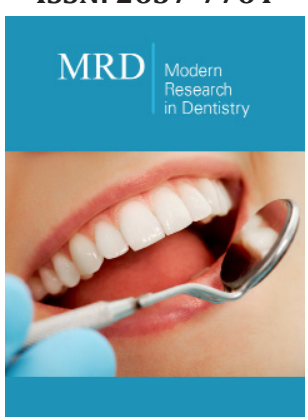

*Corresponding author: Oana Elena Amza, Carol Davila University of Medicine and Pharmacy of Bucharest, Faculty of Dentistry, 8 Eroii Sanitari Blvd, 050474, Bucharest, Romania

Ruxandra Voinea Georgescu, University Titu Maiorescu of Bucharest, Faculty of Dental Medicine, 67A Gheorghe Petrascu Str, 031593, Bucharest, Romania

Submission:

Published: 眥 September 10, 2020

Volume 5 - Issue 3

How to cite this article: Adela-Nicoleta Cenușoiu, Oana Elena Amza, Ruxandra Voinea Georgescu, et al. Retrospective from the Literature on the Clinical Implications of the Application of Physiognomic Fillings. Mod Res Dent. 5(3). MRD. 000615. 2020. DOI: 10.31031/MRD.2020.05.000615

Copyright@ Oana Elena Amza and Ruxandra Voinea Georgescu, This article is distributed under the terms of the Creative Commons Attribution 4.0 International License, which permits unrestricted use and redistribution provided that the original author and source are credited.
Adela-Nicoleta Cenușoiu' ${ }^{1}$, Ionela Teodora Dascălư², Oana Elena Amza ${ }^{3 *}$, Lelia Mihaela Gheorghiță ${ }^{2}$, Oana Andreea Diaconu², Marilena Bătăiosu², Ruxandra Voinea Georgescuí ${ }^{4}$, Cristian Niky Cumpătă ${ }^{4}$ and Mihaela Jana Tuculină ${ }^{2}$

${ }^{1}$ PhD Student, University of Medicine and Pharmacy of Craiova, Faculty of Dentistry, 2-4 Petru Rareș Str, 200349, Craiova, Romania

${ }^{2}$ University of Medicine and Pharmacy of Craiova, Faculty of Dentistry, 2-4 Petru Rareș Str, 200349, Craiova, Romania

${ }^{3}$ Carol Davila University of Medicine and Pharmacy of Bucharest, Faculty of Dentistry, 8 Eroii Sanitari Blvd, 050474, Bucharest, Romania

${ }^{4}$ University Titu Maiorescu of Bucharest, Faculty of Dental Medicine, 67 A Gheorghe Petrascu Str, 031593, Bucharest, Romania

\begin{abstract}
This study is a review of the literature to obtain a synthetic and current perspective on the clinical implications of the application of physiognomic fillings. To carry out the study, a number of 62 articles and specialized books were studied (see bibliography), these being included in the bibliographic references. Dental caries are undoubtedly one of the major oral problems, with a wide global spread and a huge impact on the lives of individuals [1]. Although the prevalence of carious lesions still reaches high values, to which we add the presence of dental lesions of a non-carious nature, the dental treatments applied are much lower. The physiognomic aspect among dental treatments has become a desideratum, especially for young patients, for whom aesthetics take precedence over the functionality of restorations. Composite resin restoration materials have achieved this goal, replacing non-physiognomic and toxic fillings fromthe amalgam.
\end{abstract}

Keywords: Physiognomic fillings; Composite materials; Dentinal adhesives

\section{Introduction}

Currently, the World Health Organization estimates that carious lesions are the most common oral health problem, followed by periodontal disease and dentomaxillary abnormalities [2].

It is crucial to monitor the progress of dental injuries, regardless of their nature, by evaluating and administering dental treatments, in parallel with the implementation of programs aimed at educating patients about the importance of prevention and oral health [3].

One of the main objectives of dental treatment is to imitate teeth and design smiles in a way that is as natural and aesthetic as possible, based on the individual and specific needs of the patient. The possibilities to achieve this goal have improved significantly in the last decade through new and specific treatment methods, dental materials being constantly improved both in terms of physical and chemical properties, but also of aesthetic properties [4].

\section{Purpose of the study}

Considering the emergence of new generations of adhesive systems and the existence on the market of composite materials with different fillings and implicit properties, we considered it necessary to conduct a study to detect structural and technological differences related to these categories of materials. The review of the specialized literature had as objectives, both 
the evaluation of the materials used in making the physiognomic fillings, and the long-term evaluation of the physiognomic fillings from an aesthetic and functional point of view.

\section{Material and Method}

The present study represents a retrospective of the specialized literature, containing a number of 52 articles and specialized bookswhich were studied and included in the bibliographical references. Electronic databases were searched, including PubMed, Cochrane and Google Scholar, using keywords about possible connections between physiognomic fillings, composites and dentinal adhesives.In the case of this study, articles that derived from the results found following the searches based on keywordswere also used.

\section{Result}

In order to perform metal restorations, it was necessary to remove a quantity of hard, healthy structure to create a retentive cavity geometry, because these filling materials did not adhere to the dental hard tissues. Currently, the introduction of adhesive techniques has been a real breakthrough for restorative dentistry, allowing a much more conservative attitude towards the remaining dental tissues [5,6].

The first attempt to achieve adhesion to dental structures belongs to the Swiss chemist Oscar Hagger, who in 1949 patented in his country a product based on glycerophosphoric acid dimethacrylate, which the company "Amalgamated / De Tray" marketed under the name "Sevriton Cavity Seal "Together with the product" Sevriton", a self-curing acrylic resin used for coronary restorations [7].

Contemporary dental adhesives show immediate favorable results in terms of adhesion effectiveness. However, the durability of resin-dentin bonds remains their major problem. It seems that the simplification of adhesive techniques is detrimental to the long-term stability of the resin-tooth interface. Hydrostatic pulp pressure, dentinal fluid flowand increased dentin moisture in vital dentin, may affect the intimate interaction of certain adhesives with dental tissue [8].

Following the review of 148 articles published between 1982 and 2015, it was concluded that the degradation of the resin-dentin bond is a complex process, which involves the hydrolysis of both the resin and the collagen fibers in the hybrid layer. Collagen fibers become vulnerable to mechanical and hydraulic fatigue, as well as degradation by host-derived proteases with collagenolytic activity. Inhibition of collagenolytic activity and the use of cross-linking agents are the two main strategies for increasing the resistance of the hybrid layer to enzymatic degradation [9].

Making an adhesive bond between enamel, dentin and restorative materials was one of the goals achivied by researchers. Adhesive systems have been classified into generations, with the first generations showing insecure connections between dental tissues and restorative material [10].
With changing technologies, dental adhesives have evolved from total-etch systems ( $4^{\text {th }}$ and $5^{\text {th }}$ generation) to self-etch systems $\left(6^{\text {th }}\right.$, $7^{\text {th }}$ and $8^{\text {th }}$ generation). ). Currently, adhesion to dental substrates is based on three different strategies: etch-and-rinse, self-etch and glass-ionomer-modified resin. More recently, a new family of dentin adhesives has been introduced (universal or multi-way adhesives), which can be used either as etch-and-rinse or as self-etch adhesives [11].

Three-stage adhesives (etch-and-rinse) still remain the gold standard in terms of durability. It is better to understand the fundamental process of adhesion to enamel and dentin with different adhesive techniques, factors that affect the long-term adhesion performance of modern adhesives and address current perspectives for improving bond durability [8].

Attempts have always been made to place dental adhesives on the market that are easier to use, in order to reduce working time as well as to make labor easier for inexperienced operators. However, it was concluded that a $4^{\text {th }}$ grade adhesive system is more effective than a $7^{\text {th }}$ grade one, as was concluded from test, wich showed fluctuations in adhesion on enamel/dentin, and diferences related to the experience of the subjects who applied the adhesive systems [12].

While some studies claim that $7^{\text {th }}$-generation adhesive systems are more effective than $6^{\text {th }}$-generation adhesives, there are studies that argue the opposite, claiming that their effectiveness is lower than those of $4^{\text {th }}$ and $6^{\text {th }}$ generation [13].

The composite resin technique has been introduced for more than 50 years, managing to simplify the way in which practitioners perform direct dental restorations. Currently, there are various composite resin systems, and in order to know which of them will work best, in a certain clinical situation, every dentist must be familiar with the composite resin infrastructure [14].

Having an organic and an inorganic matrix (quartz mass, aluminum oxide, zinc, zirconium, etc.), composite resins differ mainly in terms of filling. Fillers vary in particle size and manufacture. They can be hybrids, microhybrids, microfill composites and the newest with nanofill or nanocomposites [15].

One of the most important achievements of recent years, is the application of nanotechnology in the field of composite resins. The great interest in the use of nanoparticles emerges from the idea that they can be used to manipulate the structure of materials, to provide dramatic improvements to the electrical, chemical, mechanical and optical properties.

Nanocomposites, due to their small particle size and wide distribution, show an increase in the percentage of filling, resulting in reduced polymerization shrinkage, optimization of mechanical properties, such as tensile strength, compression or fracture [16]. Fillers influence the behavior of composites in different phases. Some characteristics of the filler particles: size, texture, shape, surface tension, optical index, quantity and mode of mass distribution of the composite, influence the properties of these 
materials. However, the filler particles need to be wetted with the resin, which limits the amount of filler that can be incorporated into the composite.

At the resin-filler interface, the filler particles are treated with coupling agents, which improve the bond between the resin and the inorganic particles, given that stresses occur in this area during the light curing reaction.Most physical properties are influenced by the resin-filler interface [17]. Nanocomposites are made up of two types of components: nanometric particles, respectively nanoclusters. The nanometers, represented by silicon dioxide particles, are discontinuous, non-aggregated and non-allomerated, having a diameter between $20-75 \mathrm{~nm}$.

\section{Nanoclusters can be of 2 types}

A. Spherical agglomerations consisting of discontinuous particles of zirconium oxide and silicon oxide, the primary size varying between 2-20nm;

B. Particles with an average size of $0.6 \mu \mathrm{m}$, sintered from initial discontinuous silica particles, of $75 \mathrm{~nm}$.

This type of composite, thanks to its composition and production technology, has allowed its use, both in the front and side area. Hybrid and microhybrid materials have a filler content of approximately $75 \%$ by weight in their structure. These filler particles range in size from 1 to 3 microns and include silicon dioxide particles, which are usually 0.04 microns in size. This type of material has superior tensile strength, low polymerization shrinkage, good fracture resistance and improved abrasion resistance. However, the major disadvantage of these materials is their poor polishability [18].

Regarding the efficiency of the 2 types of composites, it was found that both materials performed satisfactorily after the periodic analysis, that lasted 4 years, of class 2 fillings. In other words, no significant differences were observed. between these restoration materials. After 4 years, the marginal integrity of the fillings was preserved in a proportion of $66 \%$, while the rest of the filling was complete in a proportion of $73 \%$ [19].

In a similar study, conducted in vivo, over a period of 6 years, both molars and premolars, resulted in a success rate of $100 \%$. Neither the materials nor the location of the restoration (upper or lower jaw) had a significant influence on the clinical results according to any criteria, after six years.

Both materials behaved satisfactorily during the observation period of 6 years, in terms of marginal integrity, obturation, restoration of the point of contact, respectively the integrity of the remaining dental walls (molars were more affected than premolars). However, due to the expansion of the restorations, wear was clearly visible six years after the filling was applied [17].

Composite resins offer a conservative and cost-effective solution for many clinical situations. Manufacturers are constantly striving to improve the physical properties and ease of use of these materials. It is up to each clinician to determine what materials they prefer to use for daily clinical situations. The new nanomaterials are welcome supplements to the already refined range of composite resins available for clinical use [20].

The development and continuous evolution of light-curable dental materials, in particular those used for direct coronary restorations, is a significant advance for the dental field [21]. The mechanical properties of composite resins play a central role in the longevity of restorations. Given that most masticatory forces are in fact compressive forces, the study of the behavior of these materials at such forces is of real use [22].

In recent years, considerable progress in the field of nanotechnology has led to the emergence of nanocomposites. These materials, with superior optical and mechanical properties, are recommended for direct dental restorations, both for the anterior and posterior area. However, microhybrid composite resins, due to their optimal mechanical properties, remain an option for posterior restorations [23]. A major problem is that none of the existing composite resins are able to meet both requirements: aesthetics in the anterior area and functionality for the posterior teeth. Therefore, an attempt was made to increase the filler content and decrease the particle size in order to improve the physical properties [24,25].

The compressive strength of these two types of composites has been of concern to the literature, so that in a study conducted by Maryam Moezzyzadeh [26], a study using Filtek Z 250 (3M) (a microhybrid composite), Filtek Supreme (3M), Gradia Direct X (GC), Herculite XRV Ultra (Kerr Haw) (nanocomposites), it was concluded that a higher compressive strength was registered in the case of the microhybrid composite. Between the 3 nanocomposites, no significant differences were obtained [27].

In another similar study, which used Filtek Z250 Universal Restorative (3M ESPE), a microhybrid composite, and Filtek Z550 Universal Restorative (3M ESPE), a universal composite, nanohybrid, the compressive strength applied axially was analyzed. Filtek Z250 had the lowest value of the Young module in the compession. There were no significant differences between these materials in terms of compressive strength, however, the lowest value was recorded by Filtek Z550 [27]. Given the frequency of use of these materials, this study is of important relevance in selecting the appropriate type of composite material in the orthopedic stage of dental caries treatment, given that the dento-alveolar complex acts mainly compressive forces.

\section{Conclusion}

Considering the importance of dental fillings, it is imperative to continue the process of development and application of optimized materials and techniques to stop the progression of carious disease and the appearance of more advanced lesions or even loss of vitality of the dental pulp. Contemporary dental adhesives show immediate favorable results in terms of adhesion effectiveness. However, the durability of resin-dentin bonds is their major problem. There is a need to continue research on composite materials that offer both a remarkable aesthetics and resistance to masticatory forces. 


\section{Contribution Note}

All the authors equally contributed to the drawing up of the present paper.

\section{References}

1. Shams Kazi AQ Iqbal W, Sattar S (2014) Prevalence of dental caries; Patients attending out patient deparment of Isra Dental College Hospital, Shaikh, Professional Med J 21(4): 750-754.

2. Guo L, Feng Y, Guo HG, Liu BW, Zhang Y (2016) Consequences of orthodontic treatment in malocclusion patients clinical and microbial effects in adults and children. BMC Oral Health 16(1): 112.

3. Dhar V, Jain A, Van Dyke TE, Kohli A (2007) Prevalence of dental caries and treatment needs in the school-going children of rural areas in Udaipur district. J Indian Soc Pedod Prev Dent 25(3): 119-121.

4. Blatz MB, Chitche G, Bahat O, Roblee R, Coachman C (2019) Evolution of aesthetic dentistry. J Dent Res 98(12):1294-1304.

5. Terry DA, Leinfelder KF (2007) Composite resin restorations: A simplified approach.

6. Lutz F (1996) State of the art of tooth-colored restoratives. Oper Dent 21(6): 237-248.

7. Vărlan C, Dimitriu B, Stanciu D, Suciu I, Chirilă L (2011) Situaţia actuală a adeziunii la structurile dure dentare. Ghid de adeziune amelo-dentinară pentru restaurări estetice dentare. pp. 1-52.

8. Manuja N, Nagpal R, Pandit IK (2012) Dental adhesion. Journal of Clinical Pediatric Dentistry 36(3): 223-234.

9. Frassetto A, Breschi L, Turco G, Marchesi G, Lenardaa Franklin RD, et al. (2016) Mechanisms of degradation of the hybrid layer in adhesive dentistry and therapeutic agents to improve bond durability. Dental Materials 32(2): e41-e53.

10. Burke FJ, McCaughey AD (1995) The four generations of dentin bonding. Am J Dent 8(2): 88-92.

11. Sofan E, Sofan A, Palaia G, Tenore G, Romeo U, et al. (2017) Classification review of dental adhesive systems: from the IV generation to the universal type. Ann Stomatol (Roma) 8(1): 1-17.

12. Perdigão J (2007) New developments in dental adhesion. Dent Clin North Am 51(2): 333-357.

13. Nair M, Paul J, Kumar S, Chakravarthy Y, Krishna V (2014) Comparative evaluation of the bonding efficacy of sixth and seventh generation bonding agents: An In-vitro study. J Conserv Dent 17(1): 27-30.
14. Margeas R (2012) Composite resin: A versatile, multi-purpose restorative material. Compendium of Continuing Education in Dentistry $33(1)$.

15. Buonocore MG (1955) A simple method of increasing the adhesion of acrylic materials to enamel surfaces. J Dent Res 34(6): 849-853.

16. Adrian Almași (2010) Utilizarea materialelor compozite cu nanoumplutură în restaurările coronare.

17. Chalifoux PR (2010) Direct resins: evolution, applications, and techniques. Compendium 31(special issue 5): 1-9.

18. Margeas R (2012) Composite resin: a versatile, multi-purpose restorative material. Compendium of Continuing Education in Dentistry 33(1): 4245.

19. Krämera N, Reineltb C, Richterc G, Petscheltd A, Frankenberger R (2009) Nanohybrid vs. fine hybrid composite in Class II cavities: Clinical results and margin analysis after four years. Dental Materials 25(6): 750-759.

20. Krämera N, Godoybc FG, Albert CR, Feilzer AJ, Frankenberger R (2011) Nanohybrid vs. fine hybrid composite in extended Class II cavities after six years. Dental Materials 27(5): 455-464.

21. Stansbury JW (2000) Curing dental resins and composites by photopolymerization. J Esthet Dent 12(6): 300-308.

22. Mohandesi JA, Rafiee MA, Barzegaran V, Shafiei F (2007) Compressive fatigue behavior of dental restorative composites. Dent Mater J 26(6): 827-837.

23. El Safty S, Silikas N, Watts DC (2012) Creep deformation of restorative resin-composites intended for bulk-fill placement. Dent Mater 28(8): 928-935.

24. Palin WM, Fleming GJP, Trevor Burke FJ, Marquis PM, Randall RC (2003) The reliability in flexural strength testing of a novel dental composite. J Dent 31(8): 549-557.

25. Hegde MN, Hegde P, Bhandary S, Deepika K (2011) An evalution of compressive strength of newer nanocomposite: An in vitro study. J Conserv Dent 14(1): 36-39.

26. Moezzyzadeh M (2012) Evaluation of the compressive strength of hybrid and nanocomposites. J Dent Sch 30(1): 24-29.

27. Nica I, Iovan G, Stoleriu S, Angela Ghiorghe C, Pancu G, et al. (2018) Comparative study regarding the compressive strength of different composite resins used for direct restorations. Materiale Plastice 55(3): 447-453. 